\title{
Temperature Profiles During Quenches in LHC Superconducting Dipole Magnets Protected by Quench Heaters.
}

\author{
V. Maroussov, \$. Sanfilippo, A, Sjemko \\ CERN, LHC Division, 1211 Geneva 23, Switzerland
}

\begin{abstract}
The efliciency of the magnet protection by quench heators was stulied using a nowel method which derjes the temperature prolile in a superconducting magnet during a quench from mensured woltage signals. In several Large Hadron Collider single aperture dipole models, lemperature profiles and Iemperature gradients in the magnet coil have been evaluated in the case of protection by different sets of quench heaters and different powering and protection parameters. The influence of the insulation thickness belween the quench heaters and the coil has also been considered. The results show clear correlation between the positions of quench heaters, magnet protection paramelers and temperalure profiles. This study allowed a betler understanding of the quench process mechanisms and the efficiency assessment of the different protection schemes.
\end{abstract}

\section{INTRODUCTION}

The Large Hadron Collider (LHC) main superconducting dipole magnets will store a substantial amount of electromagnetic energy [1]. In $15 \mathrm{~m}$ long dipoles $7 \mathrm{MJ}$ is stored at $8.3 \mathrm{~T}$. For this magnetic field the quench propagation velocity is equal to $20-30 \mathrm{~m} / \mathrm{s}$ and is not sufficient to make the magnet self protecting. A fast and reliable magnet protection system is therefore essential to avoid an over-voltage and/or an overheating of the magnet component in casc of quench [2]. Quench heaters are therefore included to sprend rapidly the normal zone across the coil. In order to better understand the efticiency of the magnet protection, several one-meter tong dipole models have been built and tested with various design parameters. Concerning the quench heaters the main qualitative variants were the following:

a) the positions of quench heaters were in the outer layer of the coil either at the outer radius referred to as outer fadius quenct heater (ORQH) or between the inner and the outer layer referred to as inter radius quench henters (IRQH).

b) Two insulation foils 75 and $200 \mu \mathrm{m}$ thick placed between the heater strip and the magnet coil were tested.

During each test, voltage signals were measured to derive temperature profiles and to localise the critical points in the superconducting magnet during the quench [3]. In particular this methorl determined the average temperature occurring its the hottest turn and the temperature gradient across the hottest block. These parameters were of crucial importance as it was observed that high hot spot temperatures and large temperature gradients could cause a significant performance degradation [4], The magnet protection by several sets of

Manuseript received Seprember 27, 1999. quench henters is compared here for selected short dipole magnets with 6 -blocks coil design.

\section{FXPFRMMENTAL}

["he magnet electrical circuit during a quench can be represented as an equivalent serial connection of nonlinear inductance $L_{F}(\mathrm{C})$ and a time dependent resistance $\mathrm{R}(\mathrm{t})$. At the beginning of the quench, a pure inductive voltage is measured by most of the voltage tnps. The reason is that the major part of the coil remains superconducting because the quench occurs in a limited cable length of the magnet. The first step of the method aimed to calculate the inductive vollage distribution of the coil parts from the quench recording. For the cable length between two voltage taps, the partial inductance $L_{\mathrm{n}}$ defined in (1) was calculated using heater provoked quenches (for details see [3]).

$$
L_{n}=\frac{V_{\text {istluclive }}^{\text {taps }}}{V_{\text {inductive }}^{\text {magnct }}} L_{F}(I=0)
$$

By choosing for each signal between two voltage taps the maximum vatue of each $\mathbf{L}_{x,}$, the minimum Joule heat released during the quenches could be obtained using (2).

$$
\begin{aligned}
Q(t) & =\int_{\mathrm{t}_{\mathrm{u}}}^{t} V\left(\mathrm{t}^{\prime}\right) I\left(\mathrm{t}^{\prime}\right) d \mathrm{t}^{\prime} \\
& +\frac{\mathrm{L}_{\mathrm{n}}}{\mathrm{L}_{\mathrm{E}}(0) \frac{\mathrm{J}}{2}}\left(\mathrm{~L}_{\mathrm{B}}\left[\mathrm{I}\left(\mathrm{t}_{0}\right)\right]\left[\left(\mathrm{t}_{0}\right)^{2}-\mathrm{L}_{13}[\mathrm{I}(\mathrm{t})] \mathbf{1}(\mathrm{t})^{2}\right)\right.
\end{aligned}
$$

In (2) V represents the total voltige across the magnet and $t_{0}$ a time before the quench where the magnet was still in the superconducting state.

Knowing the masses of the copper and of the superconductor and knowing the dependencier of the specific heat versus temperature, the average temperature of the part of the cable between the two voltage taps could be obtained. The advantage of this method is that one does not need to calculate the resistance of the turn which depends on the local matio between the electron mean free path with respect to the interfilament and the inter bunch spacing. The peak temperature obtained by this method is by definition lower than the hot spot temperature extracted from the commonly used MITTS method because temperatures are averaged along the cable length bounded by two voltage taps. Fig. 1 presents examples of the tomperature profiles in the coil for a natural 


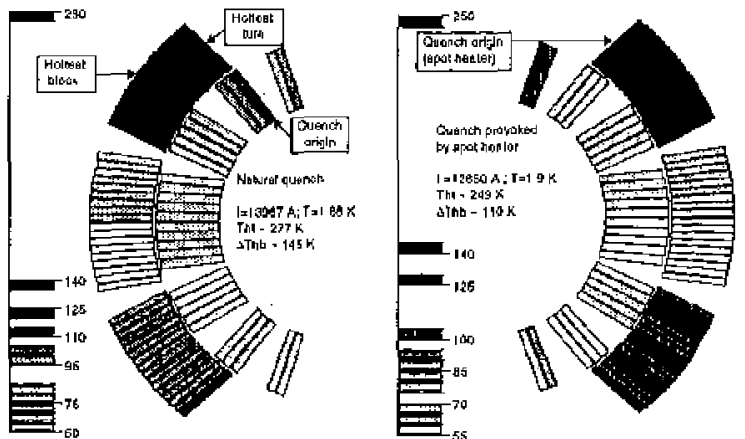

Fig. 1. Temperature profile for traiting quench without cnergy exuraction at $13967 \mathrm{~A}$ (left) and for a spot heater provoked quench at $12850 \mathrm{~A}$ (right).

quench and a quench provoked by the firing of a spot heater. Both quenches were performed without encrgy extraction.

As one can see in Fig. 1 for quenches without encrgy extraction the highest temperature was reached in the pole turn of the outer layer independent of the quench origin [5]. This particular turn of the outer layer (in the pole where the quench started), and the whole block were developing the highest temperatures. This was caused by the higher current densily of the outer layer as compared to the inner layer, coupled with the existence of a higher magnetic field in this region with respect to the rest of the outer layer. For spot henter induced quenches the similar temperature profiles werc recorded. In the following the variation of the temperature of this turn $\mathrm{T}_{\text {ht }}$ i.e. the peak temperature and the temperature difference between the polc turn and the average temperature of the related block (block 2) $\Delta \mathrm{T}_{\mathrm{hb}}$ will be considered.

$$
\Delta T_{h b}=T_{h t}-T_{b l o r k 2(\text { mernge })}
$$

where $\Delta T_{\mathrm{ll}}$ is a measure of the temperature gradient across the sixteen turns of the block 2 .

\section{RESUITS}

\section{A. Effect of the Quench Heater Position}

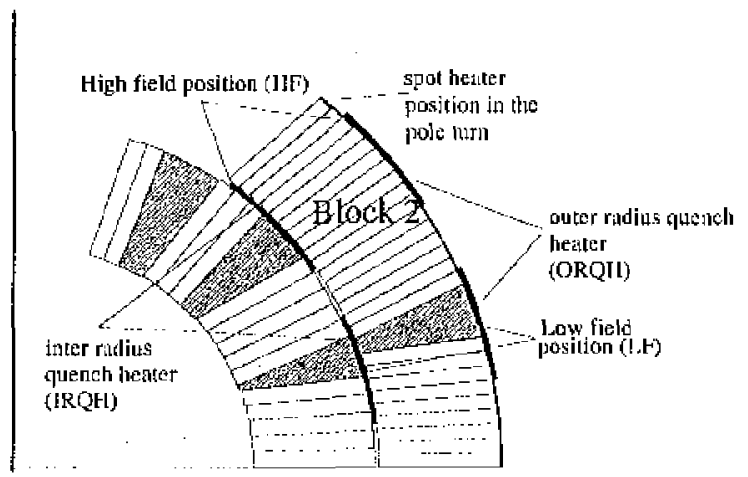

Fig 2. Layout lor a model equipped with $\mathrm{ORQH}$ and $\mathrm{IRQH}$.
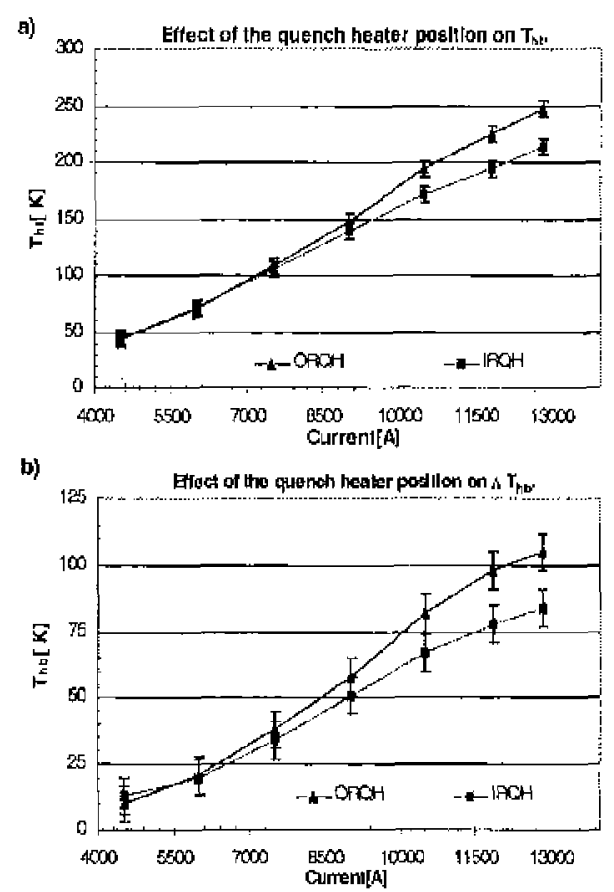

Fig. 3. Hottest tomperature (it) ind temperature gradient (b) ws current when magnet protection was performed by $1 R Q H$ or ORQ! I.

For high efficiency the heater strip must be in close thermal contact with the coil. Studies showcd that the optimum place was between the coil layers [6]-[7]-[8]. A dipole morlel was equipperl with two heating circuits between the inner and the outer layers in addition to the "elassical" heaters covering the outer radius of the outer layer. For redundancy thore were two citcuits for each type and coil quadrant. Heaters which covered the high field and the low field regions were respectively called $\mathrm{HF}$ and $\mathrm{LF}$. The insulation thickness between the coil and the quench heater (inter and outer radius) was $75 \mu \mathrm{m}$ for this test. Fig. 2 shows the position of the $\mathrm{ORQH}$ and the IRQII in the cross section of this dipole.

\section{A. I Comparison of the Peak Temperawe and of the Temperature Gradient}

The variation of $T_{h t}$ and $\Delta T_{h b}$ ws magnet current is shown in figs. $3 a$ and $3 b$ when the magnet was protected by the ORQH and the IRQH. Quenches were provoked at different cutrents by firing a spot heates located in the outer layer.

At low currents $(I<10 \mathrm{kA})$ the protection by the two types of heaters was in practice equivalent. The influence of the heater position occurred at higher currents. For an ultimate current $\mathbf{I}=12850 \mathrm{~A}$, a reduction of $35 \mathrm{~K}$ and $20 \mathrm{~K}$ was measured for $T_{h t}$ and $\Delta T_{\mathrm{lb}}$ respectively when the magnel was protected by the IRQH. This means a lowering of about $13 \%$ in terms of maximum temperature and of $20 \%$ for the temperature gradient evaluated in the holtest block. The improved efficiency of the IRQH had at least two origins. First, due to a keystone angle of the cable IRQH covers four 
unrns more than ORQH. Second, the IRQH were located in high magnetic field regions and therefore the effective temperature margin was lower and less enthalpy was needed to raise the tempernture of the coil to the critical one. The protection of the magnel using the IRQH was more efficient because the delay needed to trigger a quench was shortened.

\section{A.2 Influence on the Training Performance}

During the training, quenches without energy extraction were protected by firing successively the four outer radius and the four inter radius quench heaters. As one can soo in lig. 4 , the magnetic field level at quench dropped alter several quenches without energy extraction to two different levels $\left(D_{\text {inter }}, D_{\text {oneer }}\right)$ depending on the type of the protection. Protection by the IRQH Jimited the drop of the magnetic field to an average value of $8.7 \mathrm{~T}\left(\mathrm{D}_{\text {intor }}\right)$, and to $8.4 \mathrm{~T}\left(\mathrm{D}_{\text {ouct }}\right)$ in case of protection by the $\mathrm{ORQH}$. This de-training effect already observed for several six-block coil models had a thermo-mechanical origin induced by the coexistence of a mechanical weak region in the coil and a temperatuje rise occurring when all the stored onergy is dissipated in the magnet.

In order to evaluate the importance of the thermal effect in the instability of the training, the $\mathrm{T}_{\mathrm{m}}$ and $\Delta \mathrm{T}_{\mathrm{bb}}$ were calculated For quenches without energy extraction. As one can sce in Figs. 5a and $5 b$ a clear correlation existed between $T_{h t}$ and $\Delta \mathrm{T}_{\mathrm{h}}$ determined by the position of the quench heaters and the quench level. The drop of the magnetic field to $\mathrm{D}_{\text {outer }}$ for the increase to $D_{\text {inter }}$ ) was preceded by a quench during which the magnet was protected by the ORQI (or by the IRQH) j.e. by the quench number 33 (the quench number 38 ).

The drop to a lower magnetic ficld at quench appeared after an increase of $T_{1 t}$ and $\Delta T_{\text {hb }}$ (increase of $35 \mathrm{~K}$ and $26 \mathrm{~K}$ respectively) calculated for the case when the nilgnet was protected by the outer radius quench heaters.

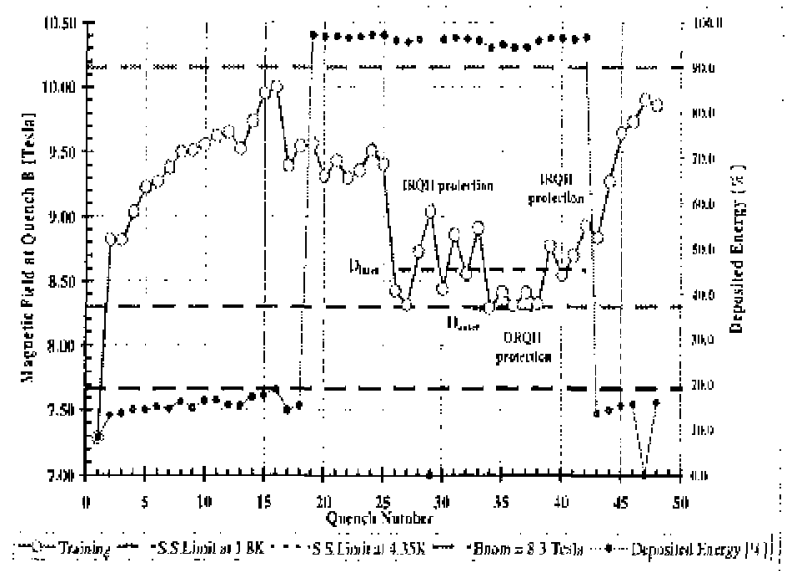

Fin. 4. Traititng curve at $1.8 \mathrm{~K}$. Tor quenches without energy extration the magnet de-trains to two different levels of magnelic liekls $D_{\text {inter and }} D_{\text {ouner }}$ depending on the type of protection.
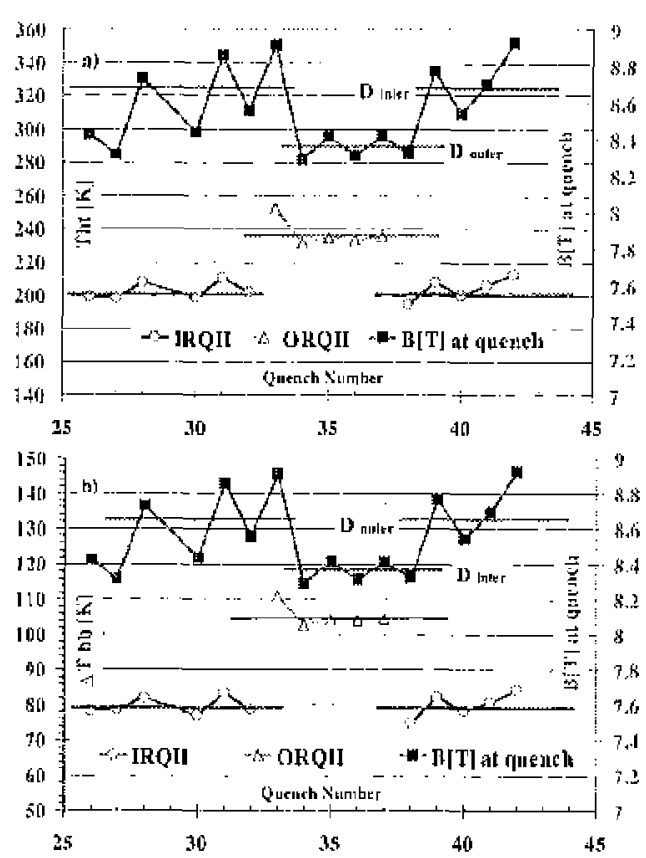

IFig. 5. Variation of $T_{h u}$ and $\Delta T_{h}$ during the training for protection by a) the IRQH b) the ORQH

\section{A.3 Protection by Different Sets of IRQH}

The efficiency of different sets high field (HI') and low field (LF) quench heaters was separately tested in the case of inter radius quench heaters (see Fig. 2 for the position of these strips). This study amed at optinisation of the protection scheme by assessing its redundancy. For quenches
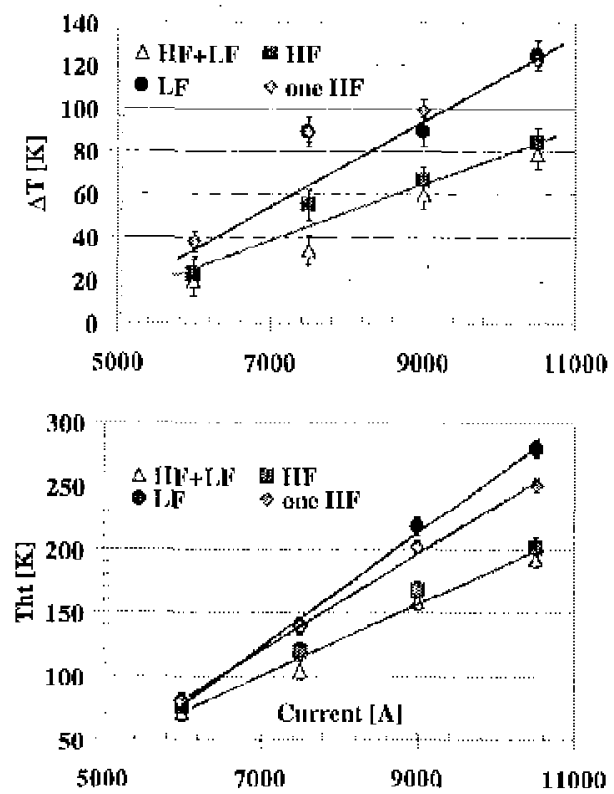

Fig. 6. Cefect of protection by several sets of IRQF on a) ' $\mathrm{l}_{\mathrm{hat}}$ and b) $\Lambda \mathrm{T}_{\mathrm{bb}}$. 
provoked by firing a spot heater, the magnet was successively protected by all the four IRQH ( $\left.\mathrm{HE}^{\mathrm{F}}+\mathrm{IF}\right)$, by only the two high field strips IRQI (IFF), by only one bigh field strip IRQH (one HF) and finally by only the two low field strips IRQI (LF). For each case the temperature profile of the magnet was determined. Figs. $6 a$ and $6 \mathrm{~b}$ present the calculated values of $T_{h t}$ and $\Delta T_{h b}$ for four cutrents i.e. for $I=6000 \mathrm{~A}, I=7500 \mathrm{~A}, I=9000 \mathrm{~A}, I=10500 \mathrm{~A}$. It was found that protection by all the heaters or only by ITF is equivalent. "This suggests that the delays till the beginning of the quenches were higher when the magnet was protected only by LF. This assumption was confirmed by the high peak temperatures and the high gradients obtained in the case of protection by only this set of heaters (Fig. 6). In the case of protection only by half high field IRQH produced temperatures which stayed well within the design specification. Thus for adequate redundancy protection by one set of HF IRQH is fully sufficient.

\section{B. Effect of the Insulation Thickness}

Two different Kapton ${ }^{\text {(9) }}$ insulation layers between the coils and the outer radius strips, $75 \mu \mathrm{m}$ thick and $200 \mu \mathrm{m}$ thick, were tested. This test aimed at investigating how the thermal conductivity between the heaters and the coil affected $T_{h_{1}}$ and $\Delta T_{\mathrm{hb}}$ Quenches were provoked by firing the spot heater and the magnet was protected by all the ORQH. Figs. $7 \mathrm{a}$ and $7 \mathrm{~b}$ stow the variation of $T_{h t}$ and of $\Delta T_{h k}$ for currents up to $13 \mathrm{kA}$. Obviously $\mathrm{T}_{\mathrm{ht}}$ and $\Delta \mathrm{T}_{\mathrm{hb}}$ increased with the insulation thickness. At high currents the increase was important and

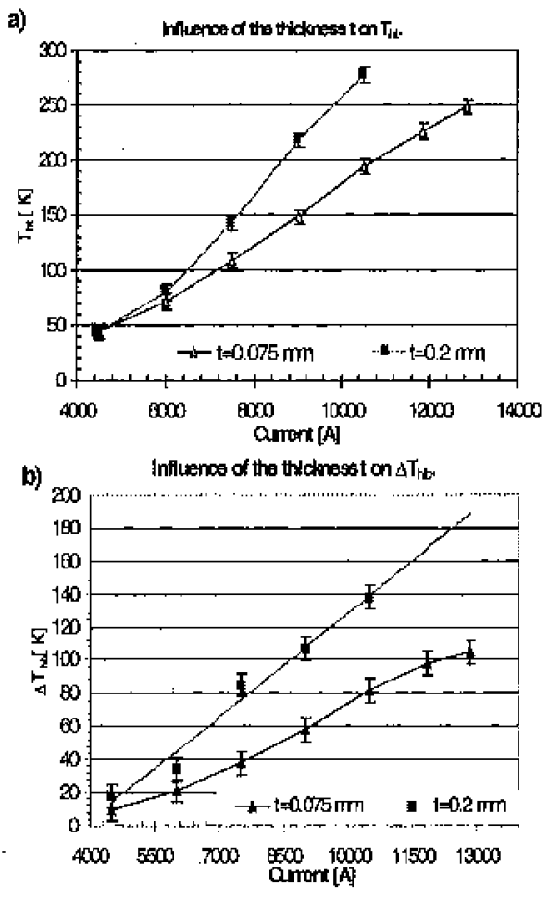

Fig. 7. Eriect of the insulation (hickness on a) $\mathrm{T}_{\mathrm{b}}$ and b) $\Delta \mathrm{T}_{\mathrm{hb}}$ equal to about $80 \mathrm{~K}$ and $54 \mathrm{~K}$ respectively. Heat tansfer was significantly slowed down by the addition of one $125 \mu \mathrm{m}$ thick sheet of Kapton and led for the nominal current (11850 A) to temperatures close to $300 \mathrm{~K}$. The measured heater delays for $200 \mu \mathrm{m}$ thick $\mathrm{ORQH}$ increased as expected by a factor of two.

\section{CONCLUSION}

The efficiency of the protection of a selected LHC short dipole magnets by several sets of heaters has been compared. The highest temperature renched in the coil and the highest temperature gradient were considered. We find that an insulation thickness of $200 \mu \mathrm{m}$ between the heater and the coils results in peak temperatures cxceeding design maximum temperature. Protection by heaters located on the inter layer radius is much more efficient than by those located on the outer radius of the coil. In the first case protection by only high field heaters is sufficient. Evaluation of the temperature profiles during quenches was found to be very helpful in the interpretation of the guench behaviour of magnets. Strong correlation between temperature profile and the de-training effect has been demonstrated. This method is an efficient and independent crosscheck of the temperature values obtained from the MIITS method and provides results for validation of simulation models of the quench process.

\section{ACKNOWLEDGEMENT}

The authors would like to thank the MMS and the MTA tenms for building and testing the LIIC short models, F. Rodriguez-Mateos, R. Schmidt, F. Sonnemann for fruitlut discussions. In particular, we wish to thank N. Siegel and D. Tommasini for their contribution.

\section{RFFERENCES}

[1] The LHC Study GToup, "The large hadron collider conceptual design, CERN," CERN/ACI95-05 (LHC), 1995, Yollow Book.

[2] L. Coull, D. Hagendorn, V. Renzondino and F. Rodriguez-Mateos, "LIIC quencl protection system," IEEL Tranx. Magnet. 30, pp. 1525 $1529,1994$.

[3] V. Maroussov and $A$. Sicmko, "A method to cvaluate the temperitute profile in a supelconducting magnet during a quetch," IELL Trats. Applicd Superronductivity 9, pp. 1153-1156, 1998.

[4] A. Siemko et al, "Power lest results on the long models and full seate prototype of the second generation L.HC are dipoles," in ICECIG/ICMC Proce, Kitakiushu, Japan, May 1996, T. Harnyama, T. Mitsui, K. Yamafuji, Eds Llsevier Science, pp. 837-842, 1997.

[5] F. Rodriguez-Matens, R. Schmidt, F. Sonneman and A. Siemko, "Quencl: process and protection of the LHC dipole magnets," CERNLIC Project Note 184, 1999.

[6] G. Ginetis and A Stevens, "Result of quench protection experiment on DM1-031," SSC T'ech Note 12, BNL, 1984.

[7] I.. Botutra el al., "Performance ol" the 1-meter model of the $70 \mathrm{~mm}$ aperture quadrupole for the 1.HC low-beta insertions." CERN-LHC Projcet Report-240, 1998.

[8] F. Chapuis,"Modélisation dn comportement ólectrothermin̨ue des aimants supraconducteurs en cas de transition resistive," DFA report LFC, 1998. 